\title{
Socio-Economic Impact Research of Foundry Industry By using Neural Network
}

\author{
Ranjitsinh A. Deshmukh, Rahul Hiremath, Gurudas Nulkar
}

\begin{abstract}
Global casting production reached 104.4 million tons in 2016. The top ten casting production nation produces 91.6 million metric tons of the total production of 104.4 million metric tons. Nearly 47.2 million metric tons of casting produces by China. Casting production increases from $5.4 \%$ to $11.35 \%$ million metric tons. USA, Japan, Germany, Russia, Korea, Mexico, Brazil and Italy are the top ten nations. Almost 6500 foundry units are in country out of which $90 \%$ can be categorized as small scale units, medium scale units as $8 \%$ and large scale units as $2 \%$. Foundry industry includes several critical aspects related to social, economic and environmental aspect need to assess. The results gained by these models are compared with regression model. Socio- economic foundry industry complex relationship between different parameters can be modeled by using neural network and regression model. It can also study running such program lead to substantial improvements in socioeconomic circumstances of targeted industry and make it sustainable industry.
\end{abstract}

Keywords- Neural Network, Regression analysis, Sustainability etc.

\section{INTRODUCTION}

Approximately 26 million Micro, Small and Medium Enterprises (MSMEs) provide 60 million people employment in the Indian economy. Almost 6500 foundry units are in country out of which $90 \%$ can be categorized as small scale units, medium scale units as $8 \%$ and large scale units as $2 \%$. Nearly 5500 enterprises in India located at 47 urban clusters. There are some challenges in front of foundry industry such as energy consumption, environmental, Occupational Health and Safety and sustainability. But some new projects have been scaling up MSME clusters in India to make it sustainable. It enables the adoption of social services and sustainable challenges in business.

The questionnaire used in this study contained twenty four items and the respondent needed to answer all the items using 1 to 5 Likert-type scale (1-strongly disagree ,2Disagree, 3-Neutral, 4- Agree and 5-strongly agree).

The responses were collected from managers, officers and workers of different industries (both private and public) across Solapur city, Maharashtra, India through interview and personal contacts. The opinions on twenty four items from respondents related to sustainability in industry. The list of industries was selected through accessing different

Revised Manuscript Received on September 10, 2019.

Ranjitsinh A Deshmukh, Mechanical Engineering, Walchand Institute of Technology, Solapur, Maharastra, India.

(Email: ranjitsinhdeshmukh222@gmail.com)

Dr.Rahul Hiremath, Faculty of Management, SCMHRD, SIU Pune, Maharastra ,India.

Gurudas Nulkar, Faculty of Management, SCMHRD, SIU Pune, Maharastra, India.
(Email: rahulhiremath@gmail.com)

websites, suggestions and personal contacts. The survey was conducted through different modes of collecting responses over a period of four months. A total of 215 questionnaires were sent and 199 responses (92\%) were received. Responses were screened based on completeness, rational scoring, and adherence to scale and finally 199 responses were considered for further analysis.

\section{ARTIFICIAL NEURAL NETWORK}

Artificial neural networks systems are calculating system motivated by biological networks it include animal brains These systems perform to do work by studying different examples, generally in absence of task-specific programming. The objective of the neural network was to resolve problems in the like way that human brain resolves it. The focus is on matching exact mental aptitudes, forwarding to divergences from biology such as back propagation. Now in the manufacturing field there is wide application of neural network. Operating conditions and process related variable relationship is proposed in artificial neural network. It can solve complex problems without aid of explicitly mentioned mathematical model. ANN is widely used in circumstances where complicated to derive mathematical model that relate different parameters.

\section{BACK PROPAGATION NEURAL NETWORK}

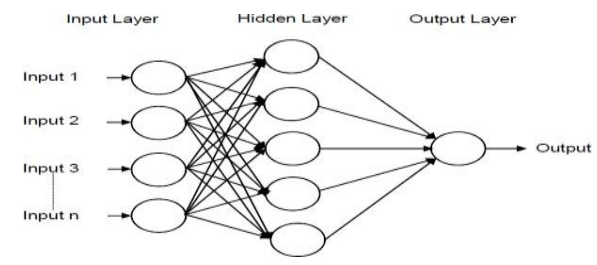

Fig.1.simple neural network

In neural network calculation of error contribution of each neuron after batch of data can be processed by using back propagation method. It can optimize algorithm to modify weight of each neuron after implementing learning process. Eventually loss function of gradient can be calculated. It is widely used in the gradient descent optimization algorithm. Error is calculated at output and spread back through neural network layers is called backward propagation of errors.

\section{NETWORK TRAINING AND DEVELOPMENT OF MODEL RESULTS}

In this neural network sigmoid function is used. The
Blue Eyes Intelligence Engineering

\& Sciences Publication 
training is carried out by using LM (Levenberg - Marquardt) with 1000 train. Matlab R205a is used for developing neural network model. There are twenty four parameters are considered for analysis (24-15-1). The architecture of neural network is prepared. The input parameters are economic,

social and environmental and sustainability is single output parameter value of dependent variable changes with variation of independent variable can be explored by using regression analysis. It can also be used for prediction and forecasting purpose. Design of experiments, pattern recognitions, factor analysis and regression analysis are methods of statistical analysis which allow analyzing the experimental data and constructing models to gain exact illustration of physical situations. In order to accurately sustainability in infrastructure development for solapur city one needs to determine the critical parameters affecting the sustainability. The Critical input Parameters affecting the melting rate are: 1. Economic 2. Social 3. Environmental.

Sustainability is taken as single output Parameter. Sustainability (S), which is a function of Economic Index

(E), Social progress index (SPI) and Environmental performance index (EPI), is as follows:

$$
\mathrm{S}=\mathrm{C} 0 \times \mathrm{R}^{\mathrm{C} 1} \times \mathrm{R}^{\mathrm{C} 2} \times \mathrm{R}^{\mathrm{C} 3}
$$

$\ln \mathrm{S}=\ln \mathrm{C} 0+\mathrm{C} 1 \ln \mathrm{E}+\mathrm{C} 2 \ln \mathrm{SPI}+\mathrm{C} 3 \ln \mathrm{EPI}$

$\mathrm{Y}=\square 0+\square 1 \mathrm{X} 1+\square 2 \mathrm{X} 2+\square 3 \mathrm{X} 3+\varepsilon$

$\mathrm{Y}=\mathrm{X} \square+\varepsilon$

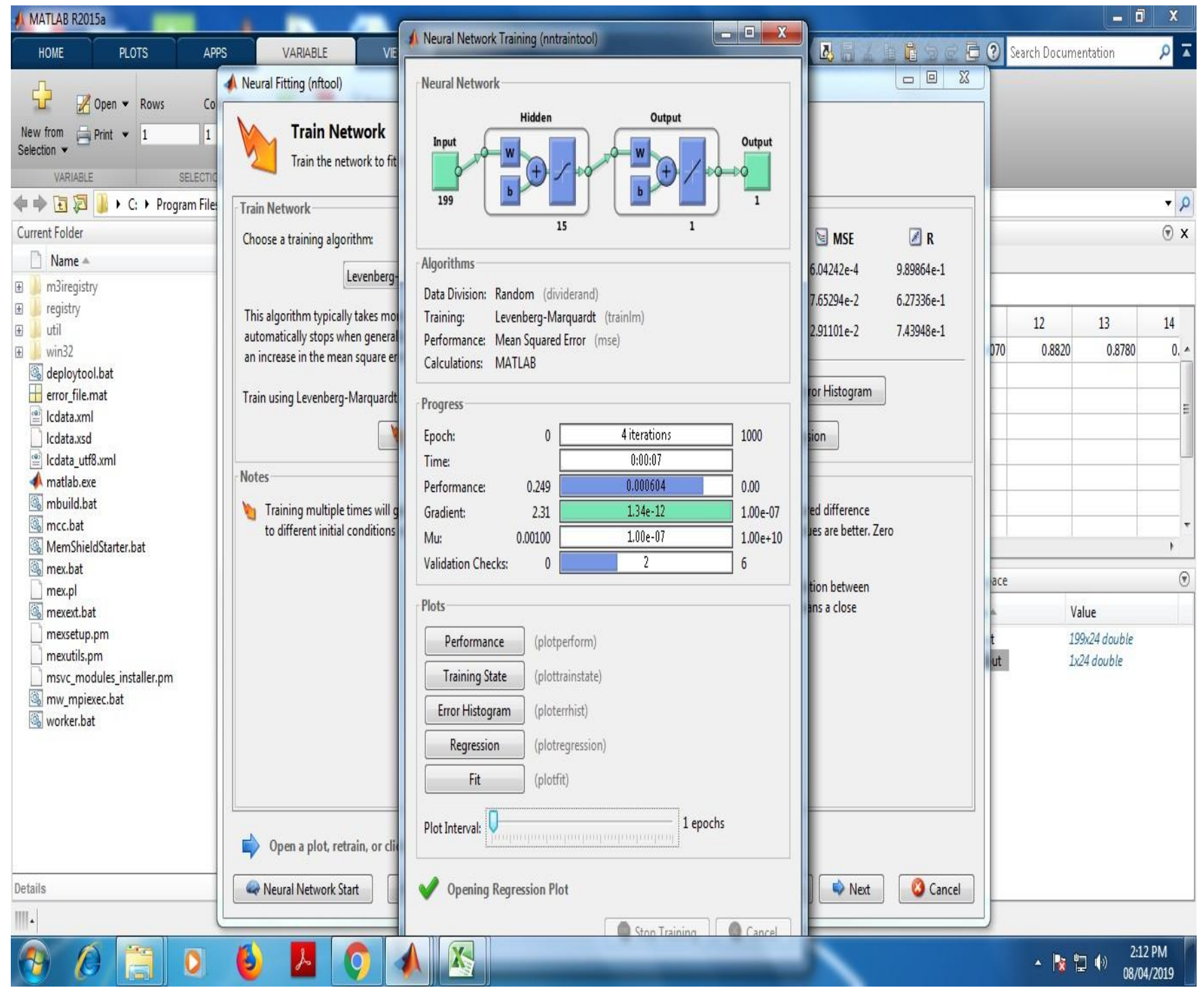

Fig.2. Networking Model 


\section{REGRESSION MODELING}

Regression is technique widely used in statistical analysis it can analyze the relationship between different factors. It involves different methods for analyzing and modeling various factors. It can also focus on dependent and independent variables with their relationships. The value of dependent variable changes with variation of independent variable can be explored by using regression analysis. It can also be used for prediction and forecasting purpose. Design of experiments, pattern recognitions, factor analysis and regression analysis are methods of statistical analysis which allow analyzing the experimental data and constructing models to gain exact illustration of physical situations. In order to accurately sustainability in infrastructure development for solapur city one needs to determine the critical parameters affecting the sustainability. The Critical input Parameters affecting the melting rate are: 1. Economic 2. Social 3. Environmental.

Sustainability is taken as single output Parameter. Sustainability (S), which is a function of Economic Index

(E), Social progress index (SPI) and Environmental performance index (EPI), is as follows:

$$
\begin{aligned}
& \mathrm{S}=\mathrm{C} 0 \times \mathrm{R}^{\mathrm{C} 1} \times \mathrm{R}^{\mathrm{C} 2} \times \mathrm{R}^{\mathrm{C} 3} \\
& \ln \mathrm{S}=\ln \mathrm{C} 0+\mathrm{C} 1 \ln \mathrm{E}+\mathrm{C} 2 \ln \mathrm{SPI}+\mathrm{C} 3 \ln \mathrm{EPI} \\
& \mathrm{Y}=\square 0+\square 1 \mathrm{X} 1+\square 2 \mathrm{X} 2+\square 3 \mathrm{X} 3+\varepsilon \\
& \mathrm{Y}=\mathrm{X} \square+\varepsilon
\end{aligned}
$$

$\sum \varepsilon \mathrm{i} 2=\sum(\mathrm{Yi}-\square 0-\square 1 \mathrm{Xi1}-\square 2 \mathrm{Xi} 2-\square 3 \mathrm{Xi3}) 2$

\section{Matrix notation as $\mathrm{X} \mathrm{TX} \beta=\mathrm{XT} \mathrm{Y}$}

$\mathrm{Y}=(\mathrm{XTX})-1 \mathrm{XTY}$

This estimates the model parameters $\{\beta 0, \beta 1, \beta 2$ and

$\beta 3\}$. Now, $\mathrm{C} 0=1041.12, \mathrm{C} 1=0.160341681, \mathrm{C} 2=-$ $0.268836005, \mathrm{C} 3=-1.255306817$

$\mathrm{S}=1041.12 \times \mathrm{R}^{0.160341681} \times \mathrm{SPI}^{-0.268836005} \times \mathrm{EPI}^{-}$

\begin{tabular}{|c|c|c|c|c|c|}
\hline EI & SPI & EPI & $\mathrm{N}^{\mathrm{AN}}$ & $\mathrm{RM}$ & $\%$ \\
\hline${ }_{5} 612$. & 49 & 889 & $45^{489 .}$ & 56 & 5.35 \\
\hline $5^{602 .}$ & 44 & 781 & $25^{518 .}$ & $23^{504 .}$ & 2.77 \\
\hline $5^{6} 605$. & 45 & 793 & $05^{512 .}$ & $48^{506 .}$ & 1.99 \\
\hline
\end{tabular}
1.255306817 SPI -1.255306817 ln EPI

Table I. Comparisons ANN \& RM

\section{A. The Social Progress Index (Spi)}

Social and environmental needs of people can be measured by using social progress index. There are 24 indicators of foundation of well-being, basic need of human and opportunity to grow the relative performance of nations. The SPI performance is measured for the well-being of environmental and social outcomes straight way rather than the economic factors. Sustainability, personal freedom, $\ln \mathrm{S}=\ln 1041.12-0.160341681 \ln \mathrm{R}--0.268836005 \ln$

safety, inclusion, equality are the factors of environmental and social index.

\section{B. Environmental Performance Index (EPI)}

Environmental performance of state's policy can be numerically and quantify by using EPI method. EPI was develop from initial environmental performance index and was circulated in 2002. Ecosystem vitality $(60 \%)$ and environmental health $(40 \%)$ are key performance indicators of EPI.

\section{Economic Index (EI)}

Economic index is very crucial term whenever company deal with sustainability index. There are different sources including prices, productivity, employment and company performance this data can be derived. There are various perspectives to track economic indices. Global Dow and NASDAQ are companies which are evaluating and predicting the economic trend.

\section{CONCLUSION}

Economic, social, and environmental index can estimate and develop sustainability model in neural network. The results gained using key performance parameters of foundry industry and ANN with LM (Levenberg - Marquardt) training for back propagation and regression analysis provide acceptable agreement with an error 5\%. The performance suggests that ANN is dominant software for forecasting and modeling applications. The ANN have appeared as a latest replacement to existing models for various processes. Results suggest that the techniques is easily put intricate relationship between various key parameters. The presented technique can open opportunities for function approximation, optimization, online control and estimation of parameters. The socio-economic impact on foundry industry for infrastructure development is very crucial looking at sustainability perspective.

\section{REFERENCES}

1. Anuwat Pansuwan March 18 - 20, 2009, Hong Kong Temperature Estimation of Liquid Steel in Induction Furnace", Proceedings of the International Multi Conference of Engineers and Computer Scientists 2009 Vol II IMECS 2009

2. Davis F. and M. Decrop, 1958 "Influence of Blast Input, Coke Size and Melting Coke Ratios on Cupola Performance", Foundry Trade Journal, pp. 319-325. [5] Pehle R. D., (1963). "Thermo- chemical Model of Computer Prediction of Cupola Performance", AFS Transactions, Vol. 71, pp. 580-587

3. Kardas, December 2012, "Evaluation of Efficiency of Working Time of Equip ment in Blast Furnace Department", Journal of Achievements in Materials and Manufacturing Engineering Volume 55 Issue 2 Pages 876-880

4. Pritibhushan Sinha and SubhashSaha, Chandra "An Optimum Design of the Lining of a Medium Frequency Induction Melting Furnace”, International Transactions in Operational Research Vol 5 No. 4, Pages 255-259 
5. Price, L. and McKane, A., (2009). Industrial Energy Efficiency and Climate Change Mitigation: Policies and Measures to REALIZE THE POTENTIAL IN THE INDUSTRIAL SECTOR, PREPARED IN support of the UN.

\section{AUTHORS PROFILE}

Ranjitsinh Deshmukh have complted B.E.(Mech) M.E.(mech) specialiasation in design. He is a research scholar in the Mechanical Engineering department of Walchand Institute of Technology,Solapur working under the supervision of Dr Rahul Hiremath. His current research focuses on energy conservation, sustainability,emission reduction strategies etc.Email id: ranjitsinhdeshmukh222@gmail.com

Dr. Rahul B Hiremath, B. E. (Mechanical), M. Tech. (Mechanical), Ph. D. IISc., Bangalore. Assistant Professor at the SCMHRD, India. Email id: rahulhiremath@gmail.com 